\title{
Can income-based co-payment rates improve disparity? The case of the choice between brand-name and generic drugs
}

\author{
Yuki Ito ${ }^{1 *}$, Konan Hara', Byung-Kwang Yoo ${ }^{2}$, Jun Tomio ${ }^{1}$ and Yasuki Kobayashi ${ }^{1}$
}

\begin{abstract}
Background: Higher income population tend to prefer brand-name to generic drugs, which may cause disparity in access to brand-name drugs among income groups. A potential policy that can resolve such disparity is imposing a greater co-payment rate on high-income enrollees. However, the effects of such policy are unknown. We examined how patients' choice between brand-name and generic drugs are affected by the unique income-based copayment rates in Japan; 10\% for general enrollees and 30\% for those with high income among the elderly aged 75 and over.

Methods: We drew on cross-sectional price variation among commonly prescribed 311 drugs using health insurance claims data from a large prefecture in Japan between October 2013 and September 2014 to identify between-income-group differences in responses to differentiated payments.

Results: Running 311 multivariate logistic regression models controlling individual demographics, the median estimate indicated that high-income group was $3 \%$ (odds ratio $=0.97$ ) less likely to choose a generic drug than the general-income group and the interquartile estimates ranged $0.92-1.02$. The multivariate feasible generalized least squares model indicated high-income group's higher likelihood to choose brand-name drugs than the generalincome group without co-payment rate differentiation $(p<0.001)$. Such gap in the likelihood was attenuated by $0.4 \%(p=0.027)$ with an US\$1 increase in the difference in additional payment/month for brand-name drugs between income groups - no gap with US\$10 additional payment/month. This attenuation was observed in drugs for chronic diseases only, not for acute diseases.

Conclusions: Income-based co-payment rates appeared to reduce disparity in access to brand-name drugs across income groups, in addition to reducing total medical expenditure among high-income group who shifted from brand-name drugs to generic ones due to larger drug price differences.
\end{abstract}

Keywords: Co-payment rate, Generic drugs, Disparity, Pharmaceuticals

\section{Background}

Increasing health expenditures is a serious concern among developed countries. During 2009-2016, Organisation for Economic Co-operation and Development (OECD) countries experienced a $1.4 \%$ annual average growth rate in per capita health expenditure [1], highlighting the growing need for policies which can minimize the health expenditure growth rate without harming clinical outcomes. At

\footnotetext{
* Correspondence: youkysnow@gmail.com

${ }^{1}$ Department of Public Health, Graduate School of Medicine, The University

of Tokyo, 7-3-1 Hongo, Bunkyo-ku, Tokyo 113-0033, Japan

Full list of author information is available at the end of the article
}

the same time, disparity in access to healthcare has become a major issue in reforming healthcare systems among OECD countries [2]. This indicates that healthexpenditure-based policies should not worsen disparities among the subgroups of the population to sustain feasibility of the policies.

To take control of health expenditure without worsening disparity in access to healthcare, among other objectives, all 36 OECD countries have some form of publicly subsidized health insurance that covers some or all of the population [1]. Although most of OECD countries have imposed a progressive income-based premium and/

(c) The Author(s). 2019 Open Access This article is distributed under the terms of the Creative Commons Attribution 4.0 International License (http://creativecommons.org/licenses/by/4.0/), which permits unrestricted use, distribution, and 
or a tax to finance a public insurance system, highincome enrollees are reported to have better access to healthcare than low-income ones given the common copayment rates if their health conditions are equal [3]. This general observation is consistent with Becker's (2007) assumption that even after paying a premium, the willingness to pay for healthcare services, i.e., access to healthcare for the same health conditions, differs by income [4]. Our overall research question is whether income-based co-payment rates can reduce the disparity in access to healthcare services across income groups. Specific hypotheses are explained hereafter.

To consider the impact of income-based co-payment rates, we focused on the choice between brand-name and generic drugs. When drugs are no longer under the legal obligations of a patent, the generic versions of these drugs are sold at lower prices. Although brand-name and generic drugs are assumed to have the same level of efficacy [5], higher income population may tend to prefer brand-name to generic drugs even if co-payment rate is equal across income groups [6], which would cause disparity in access to brand-name drugs among income groups (Hypothesis 1). Therefore, imposing a greater copayment rate on high-income enrollees can reduce disparity in terms of the equal access to brand-name drugs (Hypothesis 2), in addition to reducing expenditure without harming health conditions. Our hypothesis 3 is that the impact of income-based co-payment may differ between drugs treating acute and chronic conditions.

As an example of income-based co-payment rates, we used Japan's public universal insurance system where individuals aged 75 years or above are offered a $10 \%$ copayment rate for enrollees with general income, whereas a 30\% rate for enrollees with high income above a certain threshold. Since we know of no other study addressing the impact of income-based co-payment on the gap in the use of generic drugs between income groups, our empirical findings will help future insurance scheme reform in co-payment settings.

\section{Methods}

\section{Study population}

We used health insurance claims data provided by the Medical Care System of Latter-stage Elderly, which is the Japanese public insurance system for all the individuals aged 75 years or older. The data was comprised of enrollees living in one prefecture that includes one of Japan's major metropolitan areas. The data was based on 1.3 million individual members as of March 2014 and covered the period between October 1, 2013, and September 30,2014 . The study population was all the enrollees included in this data who used outpatient care, and whose prescriptions were dispensed by an external pharmacy that can minimize the potential physicians' influence on the choice of the drug $[7,8]$. Furthermore, we excluded individuals whose responses to income-based co-payment rates could be seriously influenced by the receipt of free medical care financed by two types of public assistance programs for those (a) reached the maximum out-of-pocket spending cap (i.e., about $8000-12,000$ Japanese Yen (JPY)/month) or (b) enrolled in a welfare program. The latter group of welfare recipients accounts for $1.7 \%$ of Japan's population, which is considerably smaller than those of OECD countries $[9,10]$. We exclude such individuals from our study because the marginal prices for brand-name and generic drugs are both zero for these individuals.

In Japan, dispensing generic drugs and generic substitution is governed by the following rules: Rules for Health Insurance-covered Medical Institutions and Physicians and Rules for Health Insurance-covered Dispensing Pharmacies and Pharmacists. There were some incentives for prescribing generic drugs for the medical institutions. During our study period, additional reimbursement was provided to the medical institutions when they wrote a prescription that included a drug prescribed in its name of the ingredient. The additional amount of reimbursement was $20 \mathrm{JPY}$ per prescription. Also, there were some incentives for dispensing and suggesting generic drugs for the pharmacies. During our observation period, pharmacies could receive additional reimbursement for each prescription when their generic drug dispense rate within pharmacy-month was higher than a specified threshold. The additional amount of reimbursement and corresponding thresholds were: 50 JPY (rate > 22\%), 150 JPY (rate > 30\%), 190 JPY (rate > $35 \%$ ). Also, to get a reimbursement for managing patients' prescription history (410 JPY), there was a requirement to suggest the use of generic drugs to the patient in addition to other requirements such as checking patients' compliance to their drugs' instructions and drug information provision using a notebook for prescription record. Furthermore, marketing and promotion for prescription drugs were governed by Pharmaceutical Affairs Act during our study period. We note that this law was replaced by Pharmaceuticals and Medical Devices Act in November 2014. Main point of these laws is that it is prohibited to advertise and promote prescription drugs directly to consumers. Advertising and promotion for prescription drugs are limited to health care professionals.

In 2013, the proportion of generic drugs dispensed where both brand-name and generic drugs were available was $43 \%$ [11]. Common reasons why the patients choose the brand-name drugs at the pharmacy are: patients wanted to follow the prescriptions where the physicians wrote down the brand-name product name and patients were suspicious about the effectiveness of generic drugs [12]. In addition, $46 \%$ of the drugs were prescribed by the generic name, while $49 \%$ were prescribed by the brand-name [12]. 


\section{Analytical model 1: association between drug choices and co-payment rates}

To analyze the association between the patients' choice between brand-name/generic drug and the patients' copayment rate, we conducted separate logistic regressions for each of 311 drugs as follows:

$$
\operatorname{Logit}\left(P\left(y_{i k t}=1\right)\right)=\mu_{k}+D_{i t} \beta_{k}+X_{i k t} \gamma_{k}
$$

where dependent variable $y_{i k t}$ is a dummy variable indicating a generic version of drug $k$ was dispensed for patient $i$ at prescription timing $t$.

The key covariate $D_{i t}$ is a dummy variable indicating the patient $i$ 's co-payment rate is $30 \%$ (the reference copayment is $10 \%$ ) at timing $t$. The coefficient $\beta_{k}$ is our primary interest. The co-payment rate becomes $30 \%$ if at least one elderly household member who is entitled to the Medical Care System of Latter-stage Elderly has a taxable income that exceeds 1.45 million JPY (100 JPY is approximately 1 US dollar (USD)). If the total income within the household (total of net incomes before basic deduction of all family members aged 70 or over) is below certain values, which depends on the composition of the household, enrollees can apply for reducing the rate to $10 \%$. The median household income for enrollees with 30 and $10 \%$ co-payment rates are approximately 7 million and 1 million JPY. Among the study population, 0.19 million (14\%) enrollees incurred 30\% co-payment, which was higher than the national average (6\%) [13].

We included a set of covariates for $X_{i k t}$ such as age, sex, amount of drug prescribed at $t$ (which is the total number of tablets/capsules of drug $k$ per prescription), area of patient's residence, total medical expenditure in a month (including prescription timing $t$ but excluding spending on drugs), and total spending on drugs besides drug $k$ in a month including prescription timing $t . \mu_{k}$ is a constant term. Since individuals tend to receive a prescription for the same drug repeatedly, we employed a generalized estimating equation (GEE) approach to account for the clustering responses among the same individuals. To model the within-individual correlation, we chose a working correlation matrix to have an exchangeable structure.

For the above analysis, 311 drugs were chosen according to the following criteria: (i) drugs in the form of tablets or capsules, (ii) drugs whose generic version existed in our observation period, (iii) drugs whose generic share based on the prescribed amount was at least 5\%, (iv) drugs whose number of prescriptions exceeded 12,000, and (v) drugs which are for daily use. We treated drugs with the same ingredient but different forms (e.g., tablets and capsules) or unit doses (e.g., amlodipine $2.5 \mathrm{mg}$ or amlodipine $5 \mathrm{mg}$ ) as distinct drugs.
Analytical model 2: association between price difference and disparity in access to brand-name drugs

Next, we analyzed whether price difference (between brand-name and generic drugs) is associated with the disparity in access to brand-name drugs. We conducted ordinary least squares (OLS) regression of the estimated coefficient $\hat{\beta}_{k}$ from Eq. (1) on price difference, since $\hat{\beta}_{k}$ represents disparity. The unit of analysis was each of 311 selected drugs. The equation for OLS regression is:

$$
\widehat{\beta_{k}}=\theta_{k}+\delta p_{k}+\varepsilon_{k},
$$

where $p_{\boldsymbol{k}}$ is the price difference between brand-name and generic drug of drug $k, \theta_{\boldsymbol{k}}$ is a constant term, and $\boldsymbol{\varepsilon}_{\boldsymbol{k}}$ is an error term. We reported all standard errors for OLS regression in heteroscedasticity-robust standard errors.

We defined price difference as the product of price difference per unit dose and average daily dose. The median and interquartile of price difference were 31 JPY and 16-58 JPY, respectively. In addition, we conducted feasible generalized least squares (FGLS) estimation that yields consistent standard error estimates, wherein the dependent variable is based on the estimates. The procedure follows previous literature $[14,15]$. We detailed the FGLS estimation procedure in the Additional file 1. Furthermore, we divided the drugs into two groups on the basis of their usage: acute and chronic drugs, as defined in the literature [16]. A total of 59 drugs were classified as acute drugs. We separately conducted OLS and FGLS regressions of Eq. (2) for acute and chronic drugs. Furthermore, for robustness check, we conducted OLS and FGLS regressions of Eq. (2) for chronic drugs, adding further detailed drug category dummies as explanatory variables. These dummies represent four categories of the chronic drugs: drugs for alimentary tract and metabolism, cardiovascular system, nervous system, and others. The first three are the top three categories in terms of the number of chronic drugs included in our analysis.

\section{Interpretation of the parameters}

We constructed an econometric model that predicts each patient's choice between brand-name and generic drug, which is detailed in the Additional file 1. Under our econometric model, coefficient $\beta_{k}$ of high-income group dummy from Eq. (1) addresses disparity in access to brand-name drugs (a coefficient of zero means no disparity). Negative $\theta_{k}$ from Eq. (2) suggests positive income elasticity of brand-name drug demand. On the other hand, positive $\delta$ from Eq. (2) suggests that disparity has improved under the Japanese income-based co-payment policy if income elasticity is positive. Intuitively, since larger brand-generic price difference implies larger out-of-pocket payment difference between income groups, positive $\delta$ 
means that a state of no disparity $\left(\beta_{k}=0\right)$ may be achieved under a certain out-of-pocket payment difference.

\section{Results}

\section{Summary statistics}

In our analysis of 311 drugs, we observed 1,075,819 distinct enrollees with $35,221,733$ drug prescriptions. At the individual level, the median age was 81 years, while the interquartile range was 78-86 years. Females comprised $62 \%$ of our sample and $13 \%$ reported a co-payment rate of $30 \%$. The median total health spending for outpatient care (sum of the amount spent by the enrollee and the insurer) per year, excluding expenditure on drugs, was 116,350 JPY and the total median spending on drugs per year was 121 , 838 JPY.

Table 1 presents the summary statistics for the top-five prescribed drugs in terms of the number of prescriptions: $100 \mathrm{mg}$ tablet of rebamipide, $5 \mathrm{mg}$ tablet of amlodipine, $15 \mathrm{mg}$ oral disintegrating tablet of lansoprazole, $12 \mathrm{mg}$ tablet of sennoside, and $0.5 \mathrm{mg}$ tablet of etizolam. We saw a higher mean age, amount per prescription, and medical spending in the high-income group. There was also a lower percentage of females in the high-income group. Further, generic drugs were more commonly dispensed in the general-income group for all five drugs.

\section{Results from analytical model 1}

Hypothesis 1 was partly suggested because the odds ratios for choosing generic drugs of the high-income group to the general-income group were significantly less than 1 (i.e., $\left.\hat{\beta}_{k}<0\right)$ for the top-five prescribed drugs (Table 2). The fact that estimated odds ratio being smaller than 1 is not sufficient to completely support our Hypothesis 1, since the odds ratios subsume the effect of different outof-pocket payment between income groups. The estimated odds ratios for five-top prescribed drugs ranged between 0.93 and 0.98 (four estimates with $p<0.001$ and one estimate with $p=0.038$ ). The estimated odds ratio (0.96) for rebamipide (in far left column in Table 2) indicated that patients with $30 \%$ copayment rate were $4 \%$ less likely to use a generic drug (or $4 \%$ more likely to use brand-name drug), compared to those with 10\% copayment rate, after adjusting sex, age, prescribed amount, area of patient's residence, monthly medical expenditure (excluding spending on drugs), and monthly spending on drugs besides rebamipide. In addition, females were observed to choose brand-name drugs more frequently.

Hypothesis 1 was again partly suggested because we found that 79 drugs had odds ratios significantly smaller than 1 , while only 21 out of 311 drugs had odds ratios significantly larger than 1 (Fig. 1). Among the 311 drugs,

Table 1 Summary statistics on patients for Top 5 drugs in terms of number of prescriptions

\begin{tabular}{|c|c|c|c|c|c|c|c|c|c|c|}
\hline & \multirow{2}{*}{\multicolumn{2}{|c|}{$\frac{\text { rebamipide } 100 \mathrm{mg}}{\text { Copayment rate }}$}} & \multirow{2}{*}{\multicolumn{2}{|c|}{$\frac{\text { amlodipine } 5 \mathrm{mg}}{\text { Copayment rate }}$}} & \multirow{2}{*}{\multicolumn{2}{|c|}{$\frac{\text { lansoprazole OD } 15 \mathrm{mg}}{\text { Copayment rate }}$}} & \multirow{2}{*}{\multicolumn{2}{|c|}{$\frac{\text { sennoside } 12 \mathrm{mg}}{\text { Copayment rate }}$}} & \multirow{2}{*}{\multicolumn{2}{|c|}{$\frac{\text { etizolam } 0.5 \mathrm{mg}}{\text { Copayment rate }}$}} \\
\hline & & & & & & & & & & \\
\hline & $10 \%$ & $30 \%$ & $10 \%$ & $30 \%$ & $10 \%$ & $30 \%$ & $10 \%$ & $30 \%$ & $10 \%$ & $30 \%$ \\
\hline Number of prescriptions & $1,018,112$ & 135,815 & 922,264 & 127,108 & 851,256 & 117,551 & 787,883 & 88,352 & 714,066 & 95,195 \\
\hline Generic dispensed & $46.4 \%$ & $44.1 \%^{\mathrm{e}}$ & $50.8 \%$ & $47.7 \%^{\mathrm{e}}$ & $41.7 \%$ & $38.3 \%^{\mathrm{e}}$ & $49.0 \%$ & $39.0 \%{ }^{\mathrm{e}}$ & $26.5 \%$ & $23.1 \%^{\mathrm{e}}$ \\
\hline \multicolumn{11}{|l|}{ Age, year } \\
\hline Mean & 82.9 & 82.3 & 83.2 & 82.4 & 84.5 & 83.7 & 85.3 & 84.8 & 83.3 & 82.5 \\
\hline Std. Dev. & 5.3 & 5.1 & 5.5 & 5.2 & 5.9 & 5.6 & 6.0 & 5.7 & 5.3 & 5.1 \\
\hline Female & $72.2 \%$ & $56.5 \%$ & $66.5 \%$ & $48.1 \%$ & $69.3 \%$ & $51.3 \%$ & $71.2 \%$ & $51.0 \%$ & $77.3 \%$ & $61.8 \%$ \\
\hline \multicolumn{11}{|l|}{ Amount $^{a}$, tablets/capsules } \\
\hline Mean & 51.6 & 52.0 & 31.2 & 34.7 & 28.9 & 31.9 & 43.8 & 48.3 & 38.2 & 41.5 \\
\hline Std. Dev. & 41.3 & 44.3 & 19.7 & 22.3 & 19.3 & 21.4 & 40.6 & 41.4 & 31.5 & 34.4 \\
\hline \multicolumn{11}{|c|}{ Medical spending ${ }^{b, c}, J P Y / m o n t h$} \\
\hline Mean & 27,358 & 28,883 & 20,837 & 21,279 & 27,507 & 31,314 & 25,014 & 31,681 & 24,379 & 25,244 \\
\hline Std. Dev. & 24,623 & 27,106 & 21,421 & 23,105 & 26,470 & 30,274 & 25,793 & 29,529 & 23,459 & 25,662 \\
\hline \multicolumn{11}{|c|}{ Spending on other drugs $s^{b} d, J P Y / m o n t h$} \\
\hline Mean & 25,534 & 25,637 & 21,258 & 21,745 & 27,723 & 29,779 & 23,400 & 26,886 & 23,949 & 24,410 \\
\hline Std. Dev. & 23,669 & 26,258 & 19,538 & 21,628 & 25,276 & 28,081 & 25,458 & 28,794 & 22,327 & 23,813 \\
\hline
\end{tabular}

Notes: Std. Dev. stands for standard deviation, OD stands for orally disintegrating tablet. We present summary statistics for top 5 prescribed drugs in number of prescriptions in our data. Statistics are calculated at the prescription level. The observation period is from October 2013 to September 2014 . ${ }^{\text {Ammount is the total }}$ number of tablets/capsules within each prescription. "'Medical spending" and "Spending on other drugs" are represented in Japanese yen (JPY) per month. 100 JPY is approximately 1 USD. Each spending is calculated as the sum of spending by the patient and the insurer. 'We exclude spending on drugs to calculate "Medical spending". "We exclude the drug to be analyzed in calculation of "Spending on other drugs". "The proportion of generic drugs dispensed was statistically smaller in the $30 \%$ copayment group (high-income group) than in the $10 \%$ copayment group (general-income group) ( $p<0.01$ for each of the 5 drugs) 
Table 2 Estimation results for Top 5 drugs in terms of number of prescriptions

\begin{tabular}{|c|c|c|c|c|c|c|c|c|c|c|}
\hline \multicolumn{11}{|c|}{ Dependent variable: Generic drug dispensed, Model: Logistic regression } \\
\hline & \multicolumn{2}{|c|}{ rebamipide $100 \mathrm{mg}$} & \multicolumn{2}{|c|}{ amlodipine $5 \mathrm{mg}$} & \multicolumn{2}{|c|}{ lansoprazole OD 15 mg } & \multicolumn{2}{|c|}{ sennoside $12 \mathrm{mg}$} & \multicolumn{2}{|c|}{ etizolam $0.5 \mathrm{mg}$} \\
\hline & $\overline{O R}$ & $95 \% \mathrm{Cl}$ & $\overline{\mathrm{OR}}$ & $95 \% \mathrm{Cl}$ & $\overline{\mathrm{OR}}$ & $95 \% \mathrm{Cl}$ & $\overline{\mathrm{OR}}$ & $95 \% \mathrm{Cl}$ & $\overline{\mathrm{OR}}$ & $95 \% \mathrm{Cl}$ \\
\hline \multicolumn{11}{|c|}{ Copayment rate } \\
\hline $10 \%$ & ref & & ref & & ref & & ref & & ref & \\
\hline $30 \%$ & $0.96^{\mathrm{a}}$ & $0.94-0.98$ & $0.98^{\mathrm{a}}$ & $0.97-1.00$ & $0.96^{\mathrm{a}}$ & $0.94-0.98$ & $0.93^{\mathrm{a}}$ & $0.91-0.95$ & $0.94^{\mathrm{a}}$ & $0.92-0.96$ \\
\hline \multicolumn{11}{|l|}{ Sex } \\
\hline Male & ref & & ref & & ref & & ref & & ref & \\
\hline Female & $0.85^{\mathrm{a}}$ & $0.84-0.87$ & $0.80^{\mathrm{a}}$ & $0.78-0.82$ & $0.85^{\mathrm{a}}$ & $0.83-0.87$ & 0.98 & $0.96-1.00$ & $0.80^{\mathrm{a}}$ & $0.77-0.82$ \\
\hline \multicolumn{11}{|l|}{ Age, year } \\
\hline $75-79$ & ref & & ref & & ref & & ref & & ref & \\
\hline $80-84$ & $0.89^{\mathrm{a}}$ & $0.88-0.91$ & $0.86^{\mathrm{a}}$ & $0.83-0.88$ & $0.93^{\mathrm{a}}$ & $0.90-0.96$ & 0.99 & $0.96-1.02$ & $0.93^{\mathrm{a}}$ & $0.90-0.96$ \\
\hline $85-89$ & $0.81^{\mathrm{a}}$ & $0.79-0.83$ & $0.82^{\mathrm{a}}$ & $0.80-0.85$ & $0.96^{\mathrm{a}}$ & $0.93-0.99$ & $1.06^{\mathrm{a}}$ & $1.03-1.10$ & $0.90^{\mathrm{a}}$ & $0.86-0.93$ \\
\hline 90- & $0.82^{\mathrm{a}}$ & $0.79-0.84$ & $0.85^{a}$ & $0.82-0.89$ & $1.07^{\mathrm{a}}$ & $1.03-1.11$ & $1.20^{\mathrm{a}}$ & $1.16-1.24$ & 1.01 & $0.96-1.06$ \\
\hline
\end{tabular}

Notes: OR is the odds ratio estimate, and $95 \% \mathrm{Cl}$ is the associated $95 \%$ confidence interval. "ref" indicates the reference group. OD stands for orally disintegrating tablet. This table shows the results from Eq. (1) described in the main text: logistic regression of a binary variable for generic drug dispensed on a $30 \%$ copayment rate dummy adjusting for individual characteristics conducted separately for each drug. Adjusted characteristics include sex, age, prescribed amount, area of patient's residence, monthly medical expenditure (excluding spending on drugs), and monthly spending on drugs besides the analyzed drug. Each spending is calculated as the sum of spending by the patient and the insurer. We show results for the top 5 prescribed drugs in terms of number of prescriptions in our data. ${ }^{\mathrm{a}}$ indicates significance at the $5 \%$ level

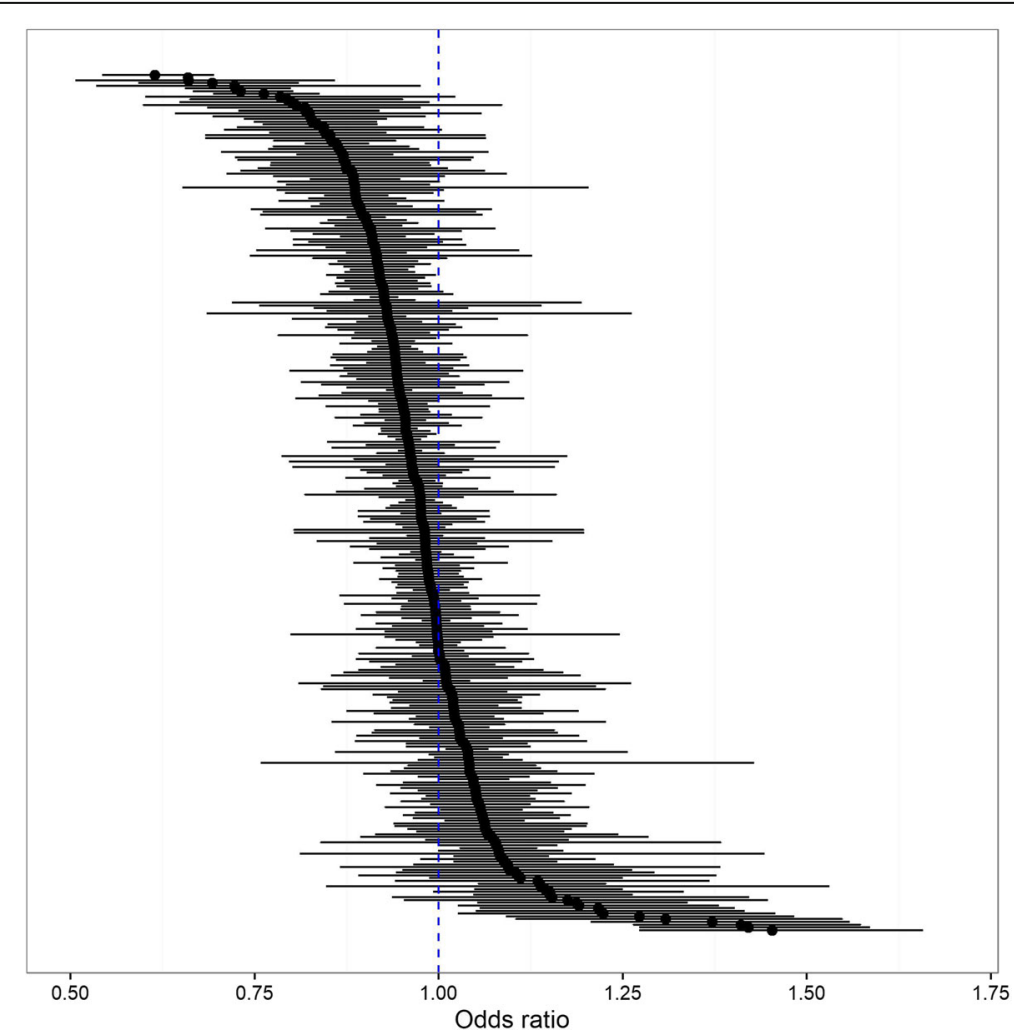

Fig. 1 Odds ratios of choosing generic drugs between high- and general-income groups for 311 drugs. Notes: This figure shows odds ratios estimated from the logistic regression Eq. (1) described in the main text for the whole sample including 311 drugs: logistic regression of a binary variable for generic drug dispensed on a 30\% co-payment rate (high-income group) dummy adjusting for individual characteristics conducted separately for each drug. Adjusted characteristics include sex, age, prescribed amount, area of patient's residence, monthly medical expenditure (excluding spending on drugs), and monthly spending on drugs besides the analyzed drug. Each spending is calculated as the sum of spending by the patient and the insurer. Estimated odds ratios for each drug are shown in filled circles. $95 \%$ confidence intervals for each drug are shown in horizontal lines. Dotted line shows where odds ratio $=1$ holds 
the median of the estimated odds ratios was 0.97 , and the interquartile range was 0.92-1.02.

\section{Results from analytical model 2}

Hypothesis 1 was supported since the estimated constant term in Eq. (2) was significantly negative, both in OLS and FGLS regressions $(p<0.001$, Columns 1 and 2 of Table 3). The estimated constant term in Eq. (2) (0.034 for FGLS) indicated that the coefficient $\beta_{k}$ would be -0.034 , suggesting patients with $30 \%$ copayment rate were $3.4 \%$ less likely to choose a generic drug compared to those with $10 \%$ copayment rate, if the price difference between brand-name and generic drugs was zero, equivalent to the case where brand-generic payment difference between income groups was zero. Furthermore, Hypothesis 2 was supported for chronic drugs, since the estimated coefficient of price difference in Eq. (2) was positive, both in OLS and FGLS regressions $(p=0.016$ and $p=0.027$, Columns 5 and 6 of Table 3). The estimated coefficient of price difference in Eq. (2) (0.023 for FGLS) indicated that an additional brand-generic price difference of $100 \mathrm{JPY} /$ day, equivalent to additional outof-pocket payment difference between income groups of $20 \mathrm{JPY} /$ day, will decrease the difference in likelihood of choosing generic drugs between income groups by $2.3 \%$ (when patients with 30\% copayment rate are less likely to choose generic drugs). Figure 2 provides a graphical illustration of the association of "price difference between brand-name and generic drugs" with "disparity in access to brand-name drugs for chronic drugs". The fitted line of Eq. (2) shown in Fig. 2 implied that state of no disparity $\left(\beta_{k}=0\right)$ can be achieved under a feasible brandgeneric price difference $(100 *(0.039 / 0.023)=170 \mathrm{JPY} /$ day $)$, which is equivalent to feasible difference in additional outof-pocket payment for a brand-name drug between income groups $(100 *(0.039 / 0.023) *(0.3-0.1)=34 \mathrm{JPY} /$ day $)$. On the other hand, for acute drugs, the estimated coefficient of price difference in Eq. (2) was statistically insignificant, supporting Hypothesis 3 ( $p=0.812$ and $p=0.821$, Columns 3 and 4 of Table 3). This insignificance indicated that brand-generic price difference, equivalent to out-of-pocket payment difference between income groups, had no significant effect on the difference in the likelihood of choosing generic drugs between income groups. In addition, our robustness-check analysis, adding further detailed drug category dummies as explanatory variables, also supported Hypothesis 1 . This is because when we added such explanatory variables, the estimated constant term was significantly negative $(p=0.017$ and $p=0.022)$ and the coefficients of drug category dummies were also negative, even though not all were statistically significant (Columns 7 and 8 of Table 3). The estimated constant term in Eq. (2) ( -0.023 for FGLS) and the estimated coefficients of drug category dummies (e.g., -0.057 for nervous system drug category dummy in FGLS) indicated that the coefficient $\beta_{k}$ would be $-0.080(=(-0.023)+(-0.057))$ for drugs categorized in the nervous system drug category, suggesting patients with $30 \%$ copayment rate were $8 \%$ less likely to choose a generic drug compared to those with $10 \%$ copayment rate, if the brand-generic price difference was zero.

\section{Discussion}

We found high-income group's higher likelihood to choose brand-name drugs than the general-income group without co-payment rate differentiation. However, income-based co-payment rates appeared to reduce disparity in access to brand-name drugs across income groups, in addition to reducing total medical expenditure among high-income group who shifted from brand-name drugs to generic ones due to larger drug price differences.

Our results suggest that high-income population tend to prefer brand-name to generic drugs more than generalincome population if co-payment rate is equal across income groups, supporting our Hypothesis 1. A study based on Danish data showed that access to brand-name drugs differs by income status, while out-of-pocket price of the drugs do not differ by their income status in Denmark. Our result follows the result from this previous study [6]. Additionally, reference-based pricing, which is a price scheme that the insurance covers cost up to a reference price, has been introduced in Denmark. In contrast to reference-based pricing, we showed that access to brandname drugs also differs by income status in an environment where both the prices for brand-name and generic drugs are partially covered by health insurance.

The results also suggest that Japan's policy of imposing higher co-payment rates for high-income elderlies than general-income ones improved disparity in terms of access to brand-name drugs relative to generic drugs between these two income groups, supporting our Hypothesis 2. Particularly, this policy effect was stronger when brandgeneric price difference is larger. Our results suggest that imposing an additional out-of-pocket payment of 1000 $\mathrm{JPY} /$ month (approximately $10 \mathrm{USD} /$ month) for brandname drugs on high-income enrollees relative to generalincome ones would result in a state of no gap in access to brand-name drugs between income groups.

Furthermore, although the policy efficacy was shown for drugs treating chronic conditions, the policy appeared to be ineffective for drugs treating acute conditions, supporting our Hypothesis 3. This result may be due to the fact that drugs for chronic conditions are repeatedly prescribed, which would provide patients with a larger number of opportunities to switch between brand-name and generic drugs, compared to drugs for acute conditions.

In our analysis for assessing the association between drug choice and co-payment rates, we controlled for individual characteristics. This allowed us to obtain precise 


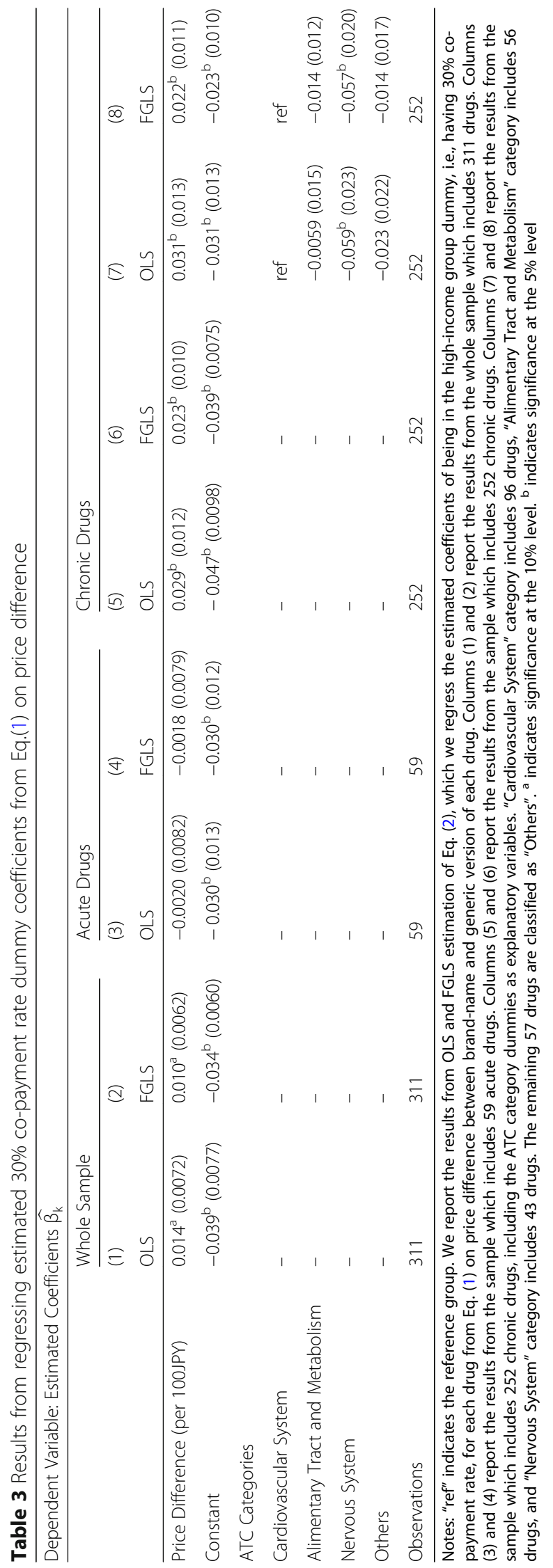




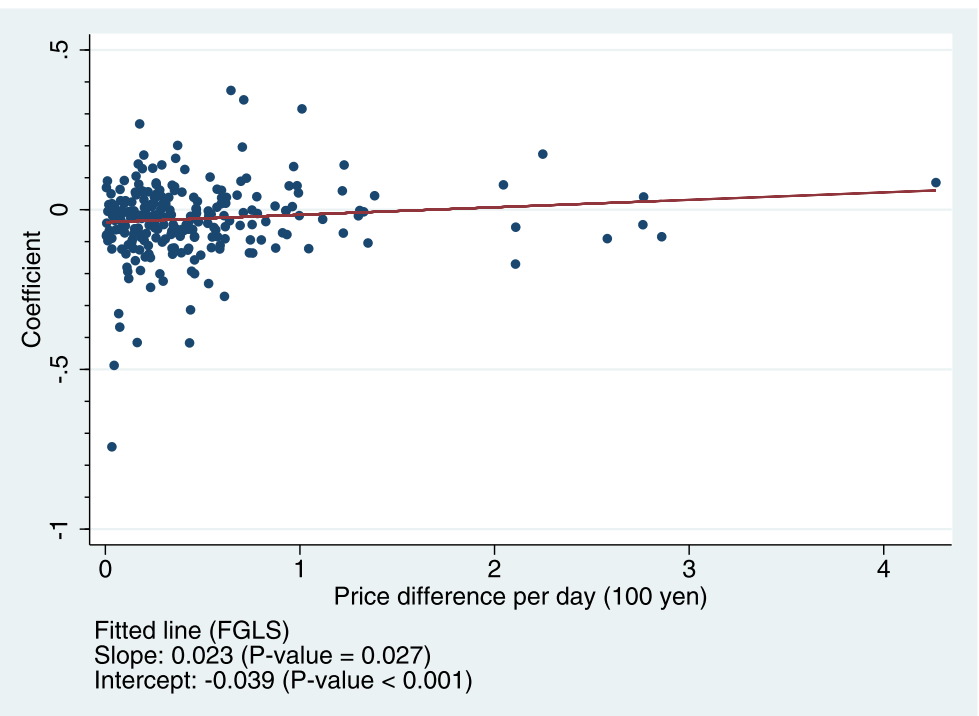

Fig. 2 Association of brand-name/generic price difference with disparity in access to brand-name drugs for chronic conditions. Notes: This figure shows the association of price difference per day between brand-name and generic drugs with disparity in access to brand-name drugs for chronic conditions. Estimated coefficients of high-income group dummy for each drug from Eq. (1) address disparity in access to brand-name drugs (a coefficient of zero means no disparity). Each filled circle represents the 252 chronic drugs. The fitted regression line is obtained from FGLS regression of Eq. (2), which corresponds to column 6 in Table 3

estimates for disparity in terms of access to brand-name drugs between two income groups $\beta_{k}$ in Eq. (1)), strengthening the internal validity of our study. In addition, the positive estimate for the effect of Japan's policy on improving disparity ( $\delta$ in Eq. (2)) was robust to adding drug-category fixed effects as control variables, also indicating the high internal validity of the study. Furthermore, the magnitude of the difference in additional outof-pocket payment (1000 JPY/month approximately equal to $10 \mathrm{USD} / \mathrm{month}$ ) for brand-name drugs between income groups that would lead to a state of no disparity appears reasonable. This is because this magnitude is well within the range of the observed payments, i.e. 3-5000 JPY/ month (approximately 0.03-50 USD/month).

Also, we expect our results to have high external validity. In our analysis, over 300 commonly prescribed drugs were analyzed. The targets of the analyzed drugs covered most of the major health conditions: chronic disease such as hypertension, dyslipidemia, and diabetes; acute conditions such as bacterial infections and acute pain. Thus, our results are expected to be valid for drugs not included in our analysis. Moreover, elderlies in Japan are mandatorily covered by one health insurance system. Therefore, there were no self-selection bias issues at the margin of obtaining insurance coverage (i.e., individuals cannot choose whether to be insured or not), strengthening external validity of our study.

Our analysis has several limitations. First, our data (between October 2013 and September 2014) did not allow us to exploit within-individual variation in co-payment rates by analyzing (a) individuals who switched between two income groups (i.e. two co-payment rates of 10 and $30 \%$ ) or (b) individuals who experienced before/after the first implementation of the income-based co-payment (rate) schemes in Japan (April 2008). Disparity estimates $\left(\beta_{k}\right.$ in Eq. (1)) could be potentially biased upward compared to true estimates if enrollees with stronger preference for brand-name drugs had intentionally reduced their income to be eligible for the general-income group. Without the additional data addressed above, we cannot verify whether such income manipulation exists. However, our Hypothesis 1 would be supported stronger without such potential upward bias.

Second, variables such as the numerical income and education levels were not included due to the limitations of the available data. Compared to the true estimates for individual-level effect of imposing higher co-payment rate on the use of generic drugs, our disparity estimates $\left(\beta_{k}\right.$ in Eq. (1)) would be biased downward. Still, our qualitative conclusion regarding hypothesis 1 holds. Moreover, our conclusion regarding Hypothesis 2 (that is more important than Hypothesis 1 for our primary research goal) is not affected by such biases.

Third, in reality, patients may choose different drugs with "similar effects," instead of switching between brand-name and generics with "same effects" examined in our analysis [17]. If such substitution across drugs with "similar effects" were prevalent, the disparity estimates $\left(\beta_{k}\right.$ in Eq. (1)) and the estimate for the effect of Japan's policy on improving disparity ( $\delta$ in Eq. (2)) could 
be biased. These biases' directions are ambiguous, since they depend on both how enrollee's income is distributed differs by drugs and how brand-name preference and income are correlated. However, although such bias may exist, the overall negative estimates for disparity suggest positive correlation between income and brandname preference, which leads to a greater disparity without co-payment differentiation. In addition, the fact that some disparity estimates (21 out of 311 ) were significantly positive $(p<0.05)$ suggest that the effect of Japan's policy is desirable in terms of reducing disparity, given highincome group has a stronger brand-name preference.

Fourth, our results are based on claims data from an area that includes a metropolitan area and a higher income population than the national average. This could lead to biased estimates of disparity $\left(\beta_{k}\right.$ in Eq. (1)) and biased estimate for the effect of Japan's policy ( $\delta$ in Eq. (2)). Again, these biases' directions are ambiguous. However, although the magnitude of our disparity estimates may be biased, our results still suggest that high-income group has a stronger brand-name preference among any population if brand-name preference is monotonously increasing with income elsewhere in Japan. Also, the policy of copayment differentiation would still improve disparity among any population provided that the highincome group's demand is price-elastic.

There is another point that is worth noting. The generic substitution rate has been increasing in Japan. This rate increased from $47 \%$ in 2013 to $73 \%$ in 2018 [11]. On the other hand, to our best knowledge, there is no study which reported how the high- and general-income population differed in terms of the change in this substitution rate during the same period. Thus, regarding our estimates on the policy impact based on the data from 2013 to 14 , the magnitude of these estimates might not be applicable to more recent data in 2018. However, the direction of our estimates is expected to be applicable for more recent data as well. That is, as long as high-income population tend to prefer brand-name to generic drugs more than general-income population without copayment differentiation, the policy should still be improving disparity.

Schneeweiss and associates examined the effects of reference-based pricing on the choice of drugs within the same drug class. Low-income patients were more likely to switch from cost-shared drugs to drugs without cost within the same drug class than high-income patients [18]. We are not able to see the effects of the Japan's policy on switching drugs due to our data limitation. However, our conclusion that the effect of Japan's policy is desirable in terms of reducing disparity would be unchanged even if patients may choose different drugs with "similar effects" as discussed above.

Additionally, Caetano and associates examined worsened disparities in access to medicines, i.e., treatment initiation and treatment discontinuity, due to the implementation of income-based drug coverage [19]. Specifically, the introduction of income-based drug coverage had no significant impact on initiation and discontinuity of hypertension/dyslipidemia treatment across income groups. However, we are not able to see the effects of the Japan's policy on treatment initiation and discontinuity due to our data limitation. Thus, we should interpret our results as the policy's effect on enrollees who continued treatment.

Our study has important policy implications. First, if co-payment rate is equal among income groups, disparity in terms of access to brand-name drugs is inevitable. This disparity may stem partly from income effect and partly from difference in perceptions of generic drugs' efficacy and safety between income groups. Since microlevel estimates for income elasticity tend to be small and even zero for some insured populations [20-22], we expect the size of income effect would be small in our analysis. Thus, providing information on generic drugs' efficacy and safety to modify such perceptions could be effective to improve disparity provided income effect is negligible among the insured population. Second, imposing higher out-ofpocket payments (may be in the form of co-payment or co-payment rates) for brand-name drugs on the highincome group can improve disparity in access to brandname drugs, particularly for drugs treating chronic conditions. If the policymaker is concerned about disparity in access to brand-name drugs, income-based co-payment (rate) schemes could be one solution. We expect such policy to be applicable and effective outside Japan.

\section{Conclusion}

High-income group has a higher likelihood to choose brand-name drugs than the general-income group without co-payment rate differentiation. Japan's policy that differentiates co-payment rate based on income reduced disparity in access to brand-name drugs across income groups. Our estimates suggest the state of no disparity would be achieved if high-income enrollees pay 10 USD/ month additionally for brand-name drugs.

\section{Supplementary information}

Supplementary information accompanies this paper at https://doi.org/10. 1186/s12913-019-4598-8.

Additional file 1. Can income-based co-payment rates improve disparity? The case of the choice between brand-name and generic drugs.

\section{Abbreviations}

FGLS: Feasible generalized least squares; GEE: Generalized estimating equation; JPY: Japanese Yen; OECD: Organisation for Economic Co-operation and Development; OLS: Ordinary least squares; USD: US Dollar 


\section{Acknowledgments}

We would like to thank Dr. Tatsuro Ishizaki, Tokyo Metropolitan Institute of Gerontology (TMIG); the Tokyo Extended Association of Medical Care System for the Latter-Stage Elderly People; and Health Information Analysis Center (HIAC) for data use authorization and preparation. In addition, we would like to thank Dr. Fumiaki Nakamura for his comments.

\section{Authors' contributions}

$\mathrm{Yl}$ performed the statistical analysis. $\mathrm{Yl}$ and $\mathrm{KH}$ conceived the idea of the study. YI, KH, BKY, JT, and YK contributed to the study design, took part in the interpretation of the results and critically revised manuscript drafts. All authors read and approved the final version of the manuscript.

\section{Funding}

This research was in part supported by the research fund from Tokyo Metropolitan Geriatric Hospital and Institute of Gerontology and JSPS KAKENHI Grant Number 18H03021.

\section{Availability of data and materials}

The datasets analyzed during the current study are not publicly available due to the contract with the Tokyo Extended Association of Medical Care System for the Latter-Stage Elderly People.

\section{Ethics approval and consent to participate}

This study protocol was reviewed by Research Ethics Committee at the Graduate School of Medicine and Faculty of Medicine, The University of Tokyo (No. 10677) and was found to comply with ethical standards.

\section{Consent for publication}

Not applicable.

\section{Competing interests}

The authors declare that they have no competing interests.

\section{Author details}

${ }^{1}$ Department of Public Health, Graduate School of Medicine, The University of Tokyo, 7-3-1 Hongo, Bunkyo-ku, Tokyo 113-0033, Japan. ${ }^{2}$ Department of Public Health Sciences, University of California, Davis, School of Medicine, One Shields Ave., Medical Sciences 1C, Davis, CA 95616, USA.

Received: 30 April 2019 Accepted: 9 October 2019

Published online: 01 November 2019

\section{References}

1. Organisation for Economic Cooperation and Development. Health at a Glance 2017. OECD; 2017.

2. van Doorslaer E, Wagstaff A, Rutten F, editors. Equity in the Finance and Delivery of Health Care: An International Perspective. Oxford: Oxford University Press; 1992.

3. Van Doorslaer E, Masseria C, Koolman X. Inequalities in access to medical care by income in developed countries. C Can Med Assoc J. 2006;174: 177-83.

4. Becker GS. Health as human capital: synthesis and extensions. Oxf Econ Pap. 2007;59:379-410

5. Kesselheim AS, Misono AS, Lee JL, Stedman MR, Brookhart AM, Choudhry NK, et al. Clinical equivalence of generic and brand-name drugs used in cardiovascular disease. JAMA. 2008;300:2514-26. https://doi.org/10.1001/ jama.2008.758

6. Skipper N, Vejlin R. Determinants of generic vs. brand drug choice: evidence from population-wide Danish data. Soc Sci Med. 2015;130:204-15. https:// doi.org/10.1016/j.socscimed.2015.01.013.

7. Liu YM, Yang YHK, Hsieh CR. Financial incentives and physicians' prescription decisions on the choice between brand-name and generic drugs: evidence from Taiwan. J Health Econ. 2009;28:341-9.

8. lizuka T. Physician agency and adoption of generic pharmaceuticals. Am Econ Rev. 2012;102:2826-58.

9. Eardley T, Bradshaw J, Ditch J, Gough I, Whiteford P. Social assistance in OECD countries. Volume I: Synthesis Report. 1996.

10. Ministry of Health Labour and Welfare. Handbook of Health and Welfare Statistics 2016, Part 3 social welfare, chapter 1 Public Assistance 2017. http:// www.mhlw.go.jp/toukei/youran/indexyk_3_1.html.
11. Ministry of Health Labour and Welfare. Promoting the Use of Generic Drugs (in Japanese). 2019. http://www.mhlw.go.jp/stf/seisakunitsuite/bunya/ kenkou_iryou/iryou/kouhatu-iyaku/index.html. Accessed 6 Aug 2019.

12. Ministry of Health Labour and Welfare. Report on the Effects and Implementation of Generic Drug Promotion Policies. 2017. https://www. mhlw.go.jp/file/05-Shingikai-12404000-Hokenkyoku-Iryouka/0000192295.pdf. Accessed 1 Mar 2019

13. Ministry of Health Labour and Welfare. Survey Report on Enrollees of Medical Care System for Elderly in the Latter Stage of Life 2016. 2017.

14. Hanushek EA. Efficient estimators for regressing regression coefficients. Am Stat. 1974;28:66-7.

15. Lewis JB, Linzer DA. Estimating regression models in which the dependent variable is based on estimates. Polit Anal. 2005;13:345-64.

16. Einav L, Finkelstein A, Schrimpf $P$. The response of drug expenditure to contract Design in Medicare Part D. Q J Econ. 2015;130:841-99.

17. Chaudhuri S, Goldberg PK, Jia P. Estimating the effects of global patent protection in pharmaceuticals: a case study of quinolones in India. Am Econ Rev. 2006;96:1477-514.

18. Schneeweiss S, Soumerai S, Glynn RJ, Maclure M, Dormuth C, Walker A. Impact of reference-based pricing for angiotensin-converting enzyme inhibitors on drug utilization. C Can Med Assoc J. 2002;166:737-45.

19. Caetano PA, Raymond CB, Morgan S, Yan L. Income-based drug coverage in British Columbia: the impact on access to medicines. Healthc Policy. 2006;2:1-16.

20. Manning WG, Newhouse JP, Duan N, Keeler EB, Leibowitz A, Marquis MS. Health insurance and demand for medical care: evidence from a randomized experiment. Am Econ Rev. 1987;77:251-77.

21. Getzen TE. Health care is an individual necessity and a national luxury: applying multilevel decision models to the analysis of health care expenditures. J Health Econ. 2000;19:259-70. https://doi.org/10.1016/S01676296(99)00032-6.

22. Newhouse JP, Phelps CE. New estimates of price and income elasticities of medical care services. In: Rosett RN, editor. The Role of Health Insurance in the Health Services Sector. New York: NBER; 1976.

\section{Publisher's Note}

Springer Nature remains neutral with regard to jurisdictional claims in published maps and institutional affiliations.

\section{Ready to submit your research? Choose BMC and benefit from:}

- fast, convenient online submission

- thorough peer review by experienced researchers in your field

- rapid publication on acceptance

- support for research data, including large and complex data types

- gold Open Access which fosters wider collaboration and increased citations

- maximum visibility for your research: over $100 \mathrm{M}$ website views per year

At BMC, research is always in progress.

Learn more biomedcentral.com/submissions 